\title{
Factors influencing mothers' health care seeking behaviour for their children: evidence from 31 countries in sub-Saharan Africa
}

Sulaimon T. Adedokun ${ }^{1}$ and Sanni Yaya ${ }^{2,3^{*}}$ (i)

\begin{abstract}
Background: Almost half of the estimated 5.3 million deaths of under-five children in 2018 occurred in subSaharan Africa with morbidity contributing substantially to these deaths. Seeking medical care for children has been described as an important measure of reducing mortality occasioned by morbidity. This study examined factors influencing mothers' health seeking behaviour for their children in sub-Saharan Africa.

Methods: This study made use of data from Demographic and Health Surveys (DHS) of 31 countries in sub-Saharan Africa. The study involved 75,982 children who received or did not receive measles vaccine and 93,142 children who sought or did not seek medical care when affected by fever or cough and diarrhoea. Binary logistic regression was applied in the analysis.

Results: Most of the children (74\%) received measles vaccine while less than one-fifth sought medical care for fever or cough (16\%) and diarrhoea (10\%). Majority of the children of women who received measles vaccine and sought medical care when they had fever or cough are from richest households. Children of women with primary and secondary or higher education, children of working women and children of women that attended antenatal care during pregnancy are more likely to seek medical care for fever or cough. While children of women who live in urban areas and children of second or higher order of birth are less likely to receive measles vaccine, children aged 24-35 months and those who were of average size at birth are less likely to seek medical care for diarrhoea.

Conclusions: This study has revealed that mothers' health care seeking behaviour for their children is influenced by social, maternal and child factors. Any intervention aimed at improving child health in sub-Sharan Africa should take these factors into consideration.
\end{abstract}

Keywords: Health care, Children, Diarrheal, Seeking behaviour, Mother, Global Health, Demographic and health surveys

\footnotetext{
* Correspondence: sanni.yaya@uOttawa.ca

${ }^{2}$ School of International Development and Global Studies, Faculty of Social Sciences, University of Ottawa, 120 University Private, Ottawa, ON K1N 6N5, Canada

${ }^{3}$ The George Institute for Global Health, The University of Oxford, Oxford, UK Full list of author information is available at the end of the article
}

(c) The Author(s). 2020 Open Access This article is licensed under a Creative Commons Attribution 4.0 International License, which permits use, sharing, adaptation, distribution and reproduction in any medium or format, as long as you give appropriate credit to the original author(s) and the source, provide a link to the Creative Commons licence, and indicate if changes were made. The images or other third party material in this article are included in the article's Creative Commons licence, unless indicated otherwise in a credit line to the material. If material is not included in the article's Creative Commons licence and your intended use is not permitted by statutory regulation or exceeds the permitted use, you will need to obtain permission directly from the copyright holder. To view a copy of this licence, visit http://creativecommons.org/licenses/by/4.0/ The Creative Commons Public Domain Dedication waiver (http://creativecommons.org/publicdomain/zero/1.0/) applies to the data made available in this article, unless otherwise stated in a credit line to the data. 


\section{Background}

Although global progress has been made in reducing child mortality, an estimated 5.3 million under-five children died in 2018 with almost half of these deaths occurring in sub-Saharan Africa [1]. Reports indicate that children in sub-Saharan Africa are more than 15 times more likely to die before age 5 than their counterparts in high income countries [2]. Morbidity contributes substantially to these deaths as pneumonia, malaria and diarrhoea have been linked to about $29 \%$ of global deaths of under-five children in 2018 [3]. While malaria resulted in approximately 266,000 deaths of these children, diarrhoea is responsible for 480,000 deaths of young children across the world [3]. In 2018, about 140, 000 measles deaths occurred globally, mostly among under-five children [4].

Seeking medical care for sick children is an important aspect of child health. Many programmes have been established in order to ensure that children receive adequate care during illness. One of such programmes is Integrated Management of Childhood Illness (IMCI) which aims at providing direction to the world child health community on the best ways to assist countries in ensuring child survival [5]. The programme has three components: (i) improving case management skills of health care staff (ii) improving overall health systems (iii) improving family and community health practices. By extension, materials were produced to assist community health workers assess and treat sick children who are between 2 and 59 months [6]. In the same vein, UNICEF introduced the Strategy for Health 2016-2030 with two overarching goals: putting an end to preventable maternal, newborn and child deaths and promoting the health and development of all children [7]. In order to achieve these goals, three key approaches were highlighted. These approaches include tackling inequities in health outcomes, strengthening health system, including emergency preparedness, response and resilience and promoting integrated, multi-sectoral policies and programmes [7].

However, despite these efforts at promoting child health, many mothers or caregivers do not seek medical care for their children [8]. This invariably constitutes threat to the survival of such children. Many factors have been linked to poor health care utilization for children. These factors include education, child's age, residence, perceived importance of early treatment, mass media exposure, level of income, birth order, socioeconomic status, occupational status [8-15]. Most of these studies focused attention on factors influencing health seeking behaviour for children in individual countries. There is a need for studies that would consider factors at regional or sub-regional level. This study aimed at filling this gap by examining mothers' health seeking behaviour for children and associated factors in subSaharan Africa as a whole.

\section{Methods \\ Study design}

This cross-sectional study was conducted in accordance with the STROBE (STrengthening the Reporting of OBservational studies in Epidemiology) recommendations. The data used in this study were obtained from Demographic and Health Surveys (DHS) of 31 countries in sub-Saharan Africa. The survey provides information on health and population issues. The countries were selected based on their most recent surveys. In order to ensure that the analysis is robust, we limited the data sets to surveys conducted between 2010 and 2018 . Table 1 shows the countries, years of survey, number of children and sex of children involved in the study.

\section{Sampling technique}

Sample selection in the surveys involved multi-stage cluster sampling method. Primary sampling unit (PSU) was adopted which divided each country into communities or clusters. Such clusters were further carved out from urban and rural areas. In each urban and rural area, households were selected for the survey. The survey involved women aged 15 to 49 years who are either permanent residents of households or visitors present at the time of the interview.

\section{Data collection}

Standardized questionnaires were used to obtain information from women aged 15-49 years. The method of data collection involved face-to-face interview with the respondents. To ensure that information was well collected, each interviewer administered a set of questionnaires in which every information provided by the respondents was recorded. Information about the children was obtained from the mothers. Some of the questions focused on socioeconomic characteristics, reproductive history, antenatal and delivery care, child health, among others.

\section{Outcome variable}

Three outcome variables have been used in this study. The first outcome variable involved children aged 1223 months who received or did not receive measles vaccine. Those who received measles vaccine were categorized as 'Yes' and those who did not receive the vaccine were categorized as 'No'. The second outcome variable is whether medical care was sought when the children had fever or cough. Children in this category were between ages 7 and 35 months. Those who sought medical care were categorized as 'Yes' and while those who did not seek medical care were categorized as 'No'. The 
Table 1 Year of survey, number of children and percentage of child sex by country in Sub-Saharan Africa

\begin{tabular}{|c|c|c|c|c|}
\hline \multirow[t]{2}{*}{ Country } & \multirow{2}{*}{$\begin{array}{l}\text { Year of } \\
\text { survey }\end{array}$} & \multirow{2}{*}{$\begin{array}{l}\text { Number of } \\
\text { children }\end{array}$} & \multicolumn{2}{|c|}{ Child sex in percentage } \\
\hline & & & Male & Female \\
\hline Angola & 2015-2016 & 3316 & 50.6 & 49.4 \\
\hline Benin & $2017-2018$ & 6042 & 50.0 & 50.0 \\
\hline Burkina Faso & 2010 & 3357 & 51.9 & 48.1 \\
\hline Burundi & $2016-2017$ & 3037 & 50.0 & 50.0 \\
\hline Cameroon & 2011 & 2744 & 49.0 & 51.0 \\
\hline Chad & 2014-2015 & 4892 & 49.5 & 50.5 \\
\hline Comoros & 2012 & 1.416 & 50.2 & 49.8 \\
\hline Congo & 2011-2012 & 2345 & 51.2 & 48.8 \\
\hline Cote d'Ivoire & $2011-2012$ & 1795 & 50.2 & 49.8 \\
\hline Democratic Republic of Congo & 2013-2014 & 4195 & 50.8 & 49.2 \\
\hline Ethiopia & 2016 & 4575 & 50.7 & 49.3 \\
\hline Gabon & 2012 & 1897 & 49.9 & 50.1 \\
\hline Gambia & 2013 & 1818 & 51.8 & 48.2 \\
\hline Ghana & 2014 & 1395 & 52.3 & 47.7 \\
\hline Guinea & 2018 & 1609 & 52.6 & 47.4 \\
\hline Kenya & 2014 & 9526 & 51.1 & 48.9 \\
\hline Lesotho & 2014 & 721 & 49.2 & 50.8 \\
\hline Liberia & 2013 & 1698 & 53.3 & 46.7 \\
\hline Malawi & 2015-2016 & 2625 & 48.4 & 51.6 \\
\hline Mali & 2018 & 4320 & 49.9 & 50.1 \\
\hline Namibia & 2013 & 1009 & 48.6 & 51.4 \\
\hline Niger & 2012 & 2658 & 50.7 & 49.3 \\
\hline Nigeria & 2018 & 5713 & 52.0 & 48.0 \\
\hline Rwanda & 2014-2015 & 1858 & 51.6 & 48.4 \\
\hline Senegal & 2010-2011 & 2159 & 54.0 & 46.0 \\
\hline South Africa & 2016 & 691 & 51.8 & 48.2 \\
\hline Tanzania & 2015-2016 & 4715 & 50.4 & 49.6 \\
\hline Togo & 2013-2014 & 1667 & 49.2 & 50.8 \\
\hline Uganda & 2016 & 2270 & 51.5 & 48.5 \\
\hline Zambia & 2018 & 4509 & 49.7 & 50.3 \\
\hline Zimbabwe & 2015 & 2570 & 49.7 & 50.3 \\
\hline
\end{tabular}

third outcome variable is whether medical care was sought when children had diarrhoea. This also involved children aged 7-35 months. Those who sought medical care were categorized as 'Yes' and those who did not seek medical care were categorized as 'No'.

\section{Independent variables}

The independent variables included in the study are mother's age, mother's education, household wealth, employment status, residence, child sex, child's age, birth order, size of child at birth and antenatal care attendance. Mother's age is categorized into 15-24 years, 25-
34 years and 35 years and above. Education was grouped into none, primary and secondary or higher. Household wealth was divided into five quintiles: poorest, poorer, middle, richer and richest. Employment status was defined as working and not working. Residence was categorized as rural and urban. Child sex was measured as male and female. Child's age has three categories, namely; 7-11 months, $12-23$ months and 24-35 months. Birth order was grouped into first order birth, second order birth and third order birth and above. Size of child at birth was defined as large, average and small. Antenatal care has two categories: did not attend and attended. 


\section{Statistical analysis}

Analysis of the data in this study involved three stages. In the first stage, weighting factor was applied to the data set of each country before pooling them tighter to arrive at a single data set for sub-Sharan Africa. This was done in order to address the problem of underenumeration and over-enumeration in the surveys. The second stage is the descriptive statistics expressed in number and percentages. At this stage, Chi-Square test was used to determine the relationships between independent variables and the outcome variables. To make the analysis easy and results obtained therefrom easily interpretable, data for the 31 countries were pooled together. The third stage involved application of binary logistic regression. It is a statistical technique used when the outcome variable is dichotomous while the independent variables may be of any form. In this case, each outcome variable is dichotomized. For instance, children who received measles vaccine were coded 1 while those who did not receive the vaccine were coded 0 . Children who sought medical care when they had fever or cough were coded 1 and those who did not seek medical care were coded 0 . Children who sought medical care when they had diarrhoea were coded 1 and those who did not seek medical care were coded 0 . The results were interpreted using odds ratio, 95\% confidence intervals and a significance level of 0.05 .

\section{Results}

\section{Descriptive statistics}

Table 1 captures demographic characteristics of respondents. The study involved 75,982 children who received or did not receive measles vaccine and 93,142 children who sought or did not seek medical care when affected by fever or cough and diarrhoea. Most of the children (74\%) received measles vaccine while less than one-fifth of the children sought medical care for fever or cough $(16 \%)$ and diarrhoea $(10 \%)$. With respect to the independent variables (Table 2), most of the children whose mothers had secondary or higher education received measles vaccine (86\%). However, majority of the children whose mothers had primary education sought medical care when they had fever or cough and diarrhoea (19 and $11 \%$ respectively). Majority of the male and female children received measles vaccine. There is no significant difference in the percentage of male and female children that sought medical care when they had fever or cough and diarrhoea. Most of the children who received measles vaccine and sought medical care when they had fever or cough are from the richest households (85 and $17 \%$ respectively). As for medical care in respect of diarrhoea, most of the children are from poorer household (11\%). Majority of the children that received measles vaccine and sought medical care when they had fever or cough live in urban areas. Most of the children that sought medical when they had fever or cough and diarrhoea were between 7 and 11 months (18 and 13\% respectively). Most of the children that received measles vaccine, sought medical care when they had fever or cough and diarrhoea belong to the first order birth category. The mothers of the majority of children who received measles vaccine and sought medical care for fever or cough and diarrhoea attended antenatal care.

\section{Multivariate analysis}

Results from the multivariate analysis (Tables 3, 4 and 5) show that children of whose mothers were 25 years and above and those who had primary and secondary or higher education are more likely to receive measles vaccine. Household wealth also shows that children from poorer, middle, richer and richest households are most likely to receive measles vaccine. Children who live in urban areas and children of second or higher birth order are less likely to receive measles vaccine. Children whose mothers are working and those who attended antenatal care are more likely to receive measles vaccine. Children who are of average size at birth are $14 \%$ more likely to receive measles vaccine compared to children who are large at birth.

For fever or cough, results show that children whose mothers had primary and secondary or higher education, are working and attended antenatal care are more likely to seek medical care for cough or fever. However, children whose mothers are 35 years and above and those living in urban areas are less likely to seek medical care for fever or cough. Also, children who are 12-23 months and above and those who are of average size at birth are less likely to seek medical care.

With respect to diarrhoea, children who are small at birth, whose mothers had primary and secondary or higher education and attended antenatal care are more likely to seek medical care for diarrhoea. Also, children of second and third order of birth or more are 14 and $15 \%$ respectively more likely to seek medical care for diarrhoea. Male children are $11 \%$ more likely to seek medical care compared to female children. Children whose mothers are 25 years and above and those from the richest households are less likely to seek medical care for diarrhoea. At the same time, children who are 24-35 months and those who are of average size at birth are less likely to seek medical care for diarrhoea.

\section{Discussion}

This study has revealed the factors which influence mothers' health care seeking behaviour for their children in sub-Saharan Africa. Results from the study show that mothers' age has a significant effect on mothers' health care seeking behaviour for their children. Children 
Table 2 Relationship between covariates and child health in Sub-Saharan Africa

\begin{tabular}{|c|c|c|c|c|c|c|}
\hline \multirow{2}{*}{$\begin{array}{l}\text { Covariates } \\
\text { Mother's age }\end{array}$} & \multicolumn{2}{|c|}{$\begin{array}{l}\text { Received measles vaccine } \\
(n=75,982)\end{array}$} & \multicolumn{2}{|c|}{$\begin{array}{l}\text { Sought medical treatment } \\
\text { for fever/cough } \\
(n=93,142)\end{array}$} & \multicolumn{2}{|c|}{$\begin{array}{l}\text { Sought medical treatment } \\
\text { for diarrhoea } \\
(n=93,142)\end{array}$} \\
\hline & No & Yes & No & Yes & No & Yes \\
\hline $15-24$ & 26.9 & 73.1 & 83.0 & 17.0 & 88.7 & 11.3 \\
\hline $25-34$ & 25.1 & 74.9 & 84.1 & 15.9 & 90.3 & 9.7 \\
\hline $35+$ & 25.4 & 74.6 & 85.3 & 14.7 & 91.5 & 8.5 \\
\hline \multicolumn{7}{|l|}{ Education } \\
\hline None & 36.6 & 63.4 & 88.1 & 11.9 & 91.4 & 8.6 \\
\hline Primary & 21.7 & 78.3 & 80.9 & 19.1 & 88.6 & 11.4 \\
\hline Sec/higher & 14.4 & 85.6 & 81.9 & 18.1 & 89.8 & 10.2 \\
\hline \multicolumn{7}{|l|}{ Household wealth } \\
\hline Poorest & 34.4 & 65.6 & 84.6 & 15.4 & 89.8 & 10.2 \\
\hline Poorer & 27.7 & 72.3 & 83.9 & 16.1 & 89.4 & 10.6 \\
\hline Middle & 24.3 & 75.7 & 83.8 & 16.2 & 90.1 & 9.9 \\
\hline Richer & 21.3 & 78.7 & 84.1 & 15.9 & 90.1 & 9.9 \\
\hline Richest & 14.9 & 85.1 & 83.1 & 16.9 & 91.0 & 9.0 \\
\hline \multicolumn{7}{|l|}{ Employment } \\
\hline Not working & 27.3 & 72.7 & 85.1 & 14.9 & 89.8 & 10.2 \\
\hline Working & 24.6 & 75.4 & 83.2 & 16.8 & 90.2 & 9.8 \\
\hline \multicolumn{7}{|l|}{ Residence } \\
\hline Rural & 27.9 & 72.1 & 84.1 & 15.9 & 89.8 & 10.2 \\
\hline Urban & 20.7 & 79.3 & 83.7 & 16.3 & 90.4 & 9.6 \\
\hline \multicolumn{7}{|l|}{ Child sex } \\
\hline Male & 25.6 & 74.4 & 83.8 & 16.2 & 89.6 & 10.4 \\
\hline Female & 25.8 & 74.2 & 84.2 & 15.8 & 90.4 & 9.6 \\
\hline \multicolumn{7}{|l|}{ Child's age } \\
\hline 7-11 months & & & 82.0 & 18.0 & 87.4 & 12.6 \\
\hline $12-23$ months & 27.2 & 72.8 & 83.1 & 16.9 & 88.4 & 11.7 \\
\hline 24-35 months & 24.1 & 75.9 & 85.9 & 14.1 & 93.0 & 7.0 \\
\hline \multicolumn{7}{|l|}{ Birth order } \\
\hline 1st order & 23.6 & 76.4 & 83.3 & 16.7 & 89.8 & 10.2 \\
\hline 2nd order & 27.5 & 72.5 & 84.8 & 15.2 & 90.0 & 10.0 \\
\hline 3rd order or more & 30.8 & 69.2 & 85.3 & 14.7 & 90.9 & 9.1 \\
\hline \multicolumn{7}{|l|}{ Size of child at birth } \\
\hline Large & 26.4 & 73.6 & 83.5 & 16.5 & 89.6 & 10.4 \\
\hline Average & 24.4 & 75.6 & 85.2 & 14.8 & 90.9 & 9.1 \\
\hline Small & 30.4 & 69.6 & 84.0 & 16.0 & 88.7 & 11.3 \\
\hline \multicolumn{7}{|l|}{ ANC attendance } \\
\hline Did not attend & 41.3 & 58.7 & 89.9 & 10.1 & 94.1 & 5.9 \\
\hline Attended & 20.1 & 79.9 & 82.1 & 17.9 & 88.7 & 11.3 \\
\hline
\end{tabular}

whose mothers are 25 years and above are more likely to receive measles vaccine compared to children of women who are 15-24 years. Results further show that this category of women (25 years and older) are less likely to seek medical care for their children whenever they are down with fever or cough and diarrhoea [16-18]. This indicates that younger women tend to take preventive measure in respect of their children while older women tend to take curative measure. With respect to education, results show that children whose mothers have primary and 
Table 3 Logistic regression of correlates of measles vaccination (12-23 months) for children in Sub-Saharan Africa

\begin{tabular}{|c|c|c|}
\hline \multirow[t]{2}{*}{ Variable } & \multicolumn{2}{|c|}{ Received measles vaccine } \\
\hline & Odds ratio & 95\% Confidence interval \\
\hline \multicolumn{3}{|l|}{ Sex of child } \\
\hline Male & 0.99 & $0.96-1.04$ \\
\hline Female & 1 & \\
\hline \multicolumn{3}{|l|}{ Mother's age } \\
\hline $15-24$ & 1 & \\
\hline $25-34$ & $1.22^{*}$ & $1.16-1.28$ \\
\hline $35+$ & $1.42^{*}$ & $1.32-1.52$ \\
\hline \multicolumn{3}{|l|}{ Education } \\
\hline None & 1 & \\
\hline Primary & $1.77^{*}$ & $1.69-1.84$ \\
\hline Sec/higher & $2.52^{*}$ & $2.39-2.66$ \\
\hline \multicolumn{3}{|l|}{ Household wealth } \\
\hline Poorest & 1 & \\
\hline Poorer & $1.21^{*}$ & $1.15-1.27$ \\
\hline Middle & $1.37^{*}$ & $1.29-1.44$ \\
\hline Richer & $1.52^{*}$ & $1.44-1.61$ \\
\hline Richest & $2.09^{*}$ & $1.95-2.26$ \\
\hline \multicolumn{3}{|l|}{ Employment } \\
\hline Not working & 1 & \\
\hline Working & $1.09^{*}$ & $1.06-1.14$ \\
\hline \multicolumn{3}{|l|}{ Residence } \\
\hline Rural & 1 & \\
\hline Urban & $0.83^{*}$ & $0.79-0.87$ \\
\hline \multicolumn{3}{|l|}{ Child's age } \\
\hline \multicolumn{3}{|l|}{ 7-11 months } \\
\hline 12-23 months & 1 & \\
\hline 24-35 months & $1.48^{*}$ & $1.43-1.54$ \\
\hline \multicolumn{3}{|l|}{ Birth order } \\
\hline 1st order & 1 & \\
\hline 2nd order & $0.88^{*}$ & $0.84-0.93$ \\
\hline 3rd order or more & $0.79^{*}$ & $0.73-0.84$ \\
\hline \multicolumn{3}{|l|}{ Size of child at birth } \\
\hline Large & 1 & \\
\hline Average & $1.14^{*}$ & $1.09-1.19$ \\
\hline Small & 0.96 & $0.92-1.02$ \\
\hline \multicolumn{3}{|l|}{ ANC attendance } \\
\hline Did not attend & 1 & \\
\hline Attended & $2.60^{*}$ & $2.50-2.70$ \\
\hline
\end{tabular}

*Level of significance at $p<0.05$

secondary or higher education are more likely to receive measles vaccine and seek medical care whenever they have fever or cough and diarrhoea. This indicates that
Table 4 Logistic regression of correlates of medical treatment for fever/cough (7-35 months) among children in Sub-Saharan Africa

\begin{tabular}{|c|c|c|}
\hline \multirow[t]{2}{*}{ Variable } & \multicolumn{2}{|c|}{ Sought medical treatment for cough/fever } \\
\hline & Odds ratio & 95\% Confidence interva \\
\hline \multicolumn{3}{|l|}{ Sex of child } \\
\hline Male & 1.04 & $0.99-1.08$ \\
\hline Female & 1 & \\
\hline \multicolumn{3}{|l|}{ Mother's age } \\
\hline $15-24$ & 1 & \\
\hline $25-34$ & 0.96 & $0.92-1.01$ \\
\hline $35+$ & $0.88^{*}$ & $0.82-0.95$ \\
\hline \multicolumn{3}{|l|}{ Education } \\
\hline None & 1 & \\
\hline Primary & $1.54^{*}$ & $1.48-1.62$ \\
\hline Sec/higher & $1.49^{*}$ & $1.42-1.57$ \\
\hline \multicolumn{3}{|l|}{ Household wealth } \\
\hline Poorest & 1 & \\
\hline Poorer & 0.98 & $0.92-1.03$ \\
\hline Middle & 0.98 & $0.93-1.04$ \\
\hline Richer & 0.95 & $0.89-1.01$ \\
\hline Richest & 0.99 & $0.93-1.07$ \\
\hline \multicolumn{3}{|l|}{ Employment } \\
\hline Not working & 1 & \\
\hline Working & $1.25^{*}$ & $1.20-1.29$ \\
\hline \multicolumn{3}{|l|}{ Residence } \\
\hline Rural & 1 & \\
\hline Urban & $0.92^{*}$ & $0.88-0.96$ \\
\hline \multicolumn{3}{|l|}{ Child's age } \\
\hline 7-11 months & 1 & \\
\hline $12-23$ months & $0.94^{*}$ & 0.89-0.99 \\
\hline 24-35 months & $0.84^{*}$ & $0.79-0.89$ \\
\hline \multicolumn{3}{|l|}{ Birth order } \\
\hline 1st order & 1 & \\
\hline 2nd order & 0.99 & $0.94-1.04$ \\
\hline 3rd order or more & 1.04 & $0.97-1.13$ \\
\hline \multicolumn{3}{|l|}{ Size of child at birth } \\
\hline Large & 1 & \\
\hline Average & $0.88^{*}$ & $0.85-0.92$ \\
\hline Small & 1.04 & $0.98-1.09$ \\
\hline \multicolumn{3}{|l|}{ ANC attendance } \\
\hline Did not attend & 1 & \\
\hline Attended & $1.68^{*}$ & $1.59-1.77$ \\
\hline
\end{tabular}

education plays a significant role in mothers' health care seeking behaviour for their children. Studies have shown that there is a direct relationship between education and 
Table 5 Logistic regression of correlates of medical treatment for diarrhoea (7-35 months) among children in Sub-Saharan Africa

\begin{tabular}{llr}
\hline Variable & \multicolumn{2}{l}{ Sought medical treatment for diarrhoea } \\
\cline { 2 - 3 } & Odds ratio & $95 \%$ Confidence interval \\
\hline
\end{tabular}

Sex of child

$\begin{array}{lll}\text { Male } & 1.11^{*} & 1.06-1.16 \\ \begin{array}{c}\text { Female } \\ \text { Mother's age }\end{array} & 1 & \\ 15-24 & 1 & \\ 25-34 & 0.86^{*} & 0.81-0.91 \\ 35+ & 0.72^{*} & 0.66-0.79\end{array}$

Education

$\begin{array}{lll}\text { None } & 1 & \\ \text { Primary } & 1.27^{*} & 1.20-1.34 \\ \text { Sec/higher } & 1.19^{*} & 1.12-1.27\end{array}$

Household wealth

$\begin{array}{lll}\text { Poorest } & 1 & \\ \text { Poorer } & 0.99 & 0.93-1.06 \\ \text { Middle } & 0.94 & 0.88-1.01 \\ \text { Richer } & 0.93 & 0.87-1.004 \\ \text { Richest } & 0.83^{*} & 0.76-0.91\end{array}$

Employment

Not working

Working

Residence

Rural

Urban

0.96

Child's age

7-11 months

12-23 months

24-35 months

Birth order

1st order

2nd order

3rd order or more

Size of child at birth

Large
Average
Small

ANC attendance

Did not attend

Attended

*Level of significance at $p<0.05$

mother's health care seeking behaviour [19-22]. This may be attributed to the fact that education exposes women to the importance of seeking health care for children. There seems to be a similar relationship in respect of household wealth as children from rich households are more likely to receive measles vaccine compared to children from poor households [23, 24]. However, children from richest households are less likely to seek medical care when they have diarrhoea. This may be linked to the fact that children from richest households may be enjoying alternative medical care such as home treatment by medical personnel. Employment status of mothers has a significant impact on health care seeking behaviour for their children as working women are more likely to present their children for measles vaccine and more likely to seek medical care when their children have fever or cough [25-27]. It may be that working women have the ability to pay for treatment whenever they present their children for medical care, something which the non-working women may not be able to do on their own.

Results further show that children in urban areas are less likely to receive measles vaccine and less likely to seek medical care when down with fever or cough [28]. This indicates that children from rural areas are more likely to receive measles vaccine and seek medical care compared to their urban counterparts. Although it is expected that children in urban areas would benefit more from medical care based on the number of health facility therein, rural dwellers may have benefitted from awareness campaign by health workers on importance of consulting medical personnel for immunization and when children are sick. Child's age is another factor that influenced health seeking behaviour of women for their children [29]. Compared to children who are 7-11 months old, children who are 12 months old and above are less likely to seek medical care when they are sick. This implies that mothers tend to pay more attention to infants than older children. This may be related to general notion that infants are yet to build immunity and as such they are more vulnerable to diseases. With respect to birth order, children of second and higher order of birth are less likely to receive measles vaccine compared to children of first order of birth [13, 30]. Whereas children of second and higher order of birth are more likely to seek medical care when they have diarrhoea. This indicates that when it comes to immunization, children of first order of birth are given preference by mothers while children of second and higher order of birth are given preference when it comes to seeking medical care during sickness.

Mothers seem to pay less attention to children who are large at birth as children who are of average size and those who are of small are more likely to receive measles vaccine and seek medical care for diarrhoea respectively. It may be that mothers perceive children who are large at birth to be strong compared to children who are either small or of average size. In fact, other studies [31] have opined that mothers considered small children to 
be fragile and as a result, they feel reluctant to present them for immunization. Antenatal care attendance tends to contribute positively to mothers' health care seeking behaviour for their children. Children of women who attended antenatal care are more likely to receive measles vaccine and seek medical care when sick. Antenatal care attendance affords women the opportunity to obtain information on maternal and child health promotion.

\section{Policy implications}

This study has shown that improvement in child health in sub-Saharan Africa requires improvement in health care seeking behaviour of women in respect of their children. Based on the findings from the study, some measures need to be taken in order to improve child health in the region. There is a need for adequate orientation and awareness creation for women at local level. Such awareness programme should be geared towards provision of useful information on issues relating to child health and enlightenment on beliefs that may be harmful to child wellbeing. For instance, young and older women should be enjoined to give priority to any aspect of their children's health, be it immunization or seeking medical care for any ailment. At the same time, women who are of the habit of not attending antenatal care whenever they are pregnant should be encouraged to attend in order to benefit from the information provided during the clinics. Also, emphasis should be placed on seeking medical care and taking up immunization for children irrespective of their size, order of birth or age. This will go a long way in eradicating preference on the basis of such factors. Efforts should be made by governments at all levels to increase proportions of educated women in the region. Although there have been programmes in different countries on improving girl-child education, areas of improvement should be maintained while areas where there are issues should be reviewed. Governments should also look into provision of employment opportunities for women who are willing to work. For those who may wish to embark on business activities or artisanship such as tailoring, hairdressing, weaving, catering services, etc. funds should be provided for them with convenient repayment period.

\section{Study strengths and weaknesses}

This study has made use of data from cross-sectional surveys which make the establishment of cause-effect to be difficult. The data sets for the countries were pooled together for easy analysis and interpretation. Some variables which might be of importance to the study were dropped because some countries did not measure them. Being hierarchical data sets, the use of multilevel analysis would have taken care of the structure. But this was not considered in the study. However, despite these shortcomings, the study is among the few that examined the relationship between mothers' health care seeking behaviour and child health at sub-Saharan African level. At the same time, the study has used large data sets which include many countries and which has made the results more robust. In view of this, results obtained can be related to other countries or regions with similar characteristics.

\section{Conclusions}

This study has revealed that mothers' health care seeking behaviour for their children is influenced by social, maternal and child factors. Any intervention aimed at improving child health in sub-Sharan Africa should take these factors into consideration.

\section{Abbreviations}

DHS: Demographic and Health Survey; IMCl: Integrated Management of Childhood IIIness; PSU: Primary Sampling Unit; UNICEF: United Nations International Children's Emergency Fund; WHO: World Health Organization

\section{Acknowledgements}

The authors thank the MEASURE DHS project for their support and for free access to the original data.

\section{Authors' contributions}

STA and SY conceptualised and designed the study, STA acquired, analysed, interpreted the data, STA and SY drafted and revised the manuscript, SY critically reviewed the manuscript. SY had final responsibility to submit for publication. Both authors approved the final manuscript as submitted and agree to be accountable for all aspects of the work.

\section{Funding}

The authors received no specific funding for this work.

\section{Availability of data and materials}

Data used in this study were obtained from the DHS Program and available at: https://dhsprogram.com/data/available-datasets.cfm.

\section{Ethics approval and consent to participate}

Ethics approval was not required for this study since the data is secondary and is available in the public domain. More details regarding DHS data and ethical standards are available at: http://goo.gl/ny8T6X.

Consent for publication

Not Applicable.

\section{Competing interests}

The authors declare that they have no competing interest.

\section{Author details}

${ }^{1}$ Department of Demography and Social Statistics, Obafemi Awolowo University, Ile-Ife, Nigeria. ${ }^{2}$ School of International Development and Global Studies, Faculty of Social Sciences, University of Ottawa, 120 University Private, Ottawa, ON K1N 6N5, Canada. ${ }^{3}$ The George Institute for Global Health, The University of Oxford, Oxford, UK.

Received: 13 May 2020 Accepted: 23 August 2020

Published online: 07 September 2020

\section{References}

1. Under-five Mortality. https://data.unicef.org/topic/child-survival/under-fivemortality/. Accessed 1 May 2020.

2. Children: Reducing Mortality. https://www.who.int/news-room/fact-sheets/ detail/children-reducing-mortality. Accessed 1 May 2020. 
3. Childhood Diseases. https:/www.unicef.org/health/childhood-diseases. Accessed 2 May 2019.

4. Measles. https:/www.who.int/news-room/fact-sheets/detail/measles Accessed 2 May 2020

5. Maternal, Newborn, Child and Adolescent Health. https:/www.who.int/ maternal_child_adolescent/topics/child/imci/en/. Accessed 2 May 2020.

6. Caring for Newborns and Children in the Community. https://www.who.int/ maternal_child_adolescent/documents/caring-for-the-sick-child/en/. Accessed 5 May 2020.

7. Strategy for Health 2016-2030. https://www.unicef.org/media/58166/file. Accessed 4 May 2020.

8. Abegaz NT, Berhe H, Gebretekle GB. Mothers/caregivers healthcare seeking behavior towards childhood illness in selected health centers in Addis Ababa, Ethiopia: a facility-based cross-sectional study. BMC Pediatr. 2019;19:220.

9. Wambui WM, Kimani S, Odhiambo E. Determinants of health seeking behavior among caregivers of infants admitted with acute childhood illnesses at Kenyatta National Hospital, Nairobi, Kenya. Int J Pediatr. 2018; 2018:1-12.

10. Simieneh MM, Mengistu MY, Gelagay AA, Gebeyehu MT. Mothers' health care seeking behavior and associated factors for common childhood illnesses, Northwest Ethiopia: community based cross-sectional study. BMC Health Serv Res. 2019;19:59.

11. Yerpude PV, Jogdand KS, Shah JH, Thacker KB. A study of factors which determine health seeking behavior of mothers for their under five children in rural area of Gujarat. Int J Community Med Public Health. 2017;4(11): 4169-73.

12. Gerald M. Assessing factors influencing health seeking behavior for malaria treatment in children under five years in Rwimi Town Council Kabarole District. Int J School Cognitive Psychol. 2015;2(4):151.

13. Mishra K, Mohapatra I, Kumar A. A study on the health seeking behavior among caregivers of under-five children in an Urban Slum of Bhubaneswar, Odisha. J Family Med Primary Care. 2019;8(2):498-503.

14. Obi-Nwosu AL, Nwosu OB, Nnaji G in a: Family and Social Determinants of Health-seeking Behaviour of Caregivers of Febrile Children Urban City of South-Eastern Nigeria. Arch Med. 2016;8(3):1-6

15. Owoyemi AJ, Ladi-Akinyemi TW. Health-seeking behaviour for infants by caregivers in a Semi-urban Area of Lagos State, Nigeria. Nigerian J Health Sci. 2017;17(1):14.

16. Ajibade BL, Amoo PO, Adeleke MA, Oyediran GO, Kolade OA, Olagunju RO Determinants of mothers health seeking behaviour for their children in a Nigerian Teaching Hospital. J Nurs Health Sci. 2013;1(6):9-16.

17. Teklay G, Alemayoh $\Pi$, Atalay HT, Mariye T. Modern health-seeking behaviour and associated factors among mothers having under 5-years old children in Shire town, Tigray, Ethiopia: a cross-sectional study 2018. African J Primary Health Care Family Med. 2020;11(1):1-6.

18. Mina K, Lija M, Jayasree S, Gehendra M. A Study to Assess the Knowledge, and Practice on Health Seeking Behaviour of Mothers During Child Illness in Rural Areas of Bangalore, India. Int J Health Sci Res. 2019;9(3):143-52.

19. Chandwani H, Pandor J. Healthcare-seeking behaviors of mothers regarding their children in a tribal community of Gujarat, India. Electron Physician. 2015;7(1):990.

20. Ghosh N, Chakrabarti I, Chakraborti M, Biswas R. Factors Affecting the Healthcare-Seeking Behavior of Mothers Regarding their Children in a Rural Community of Darjeeling District, West Bengal. Int J Med Public Health. 2013;3(1):12-6.

21. Etea TD. Mother's Perception and Treatment SeekingBbehaviour for Childhood Diarrhea in Dendi District, West Shoa, Ethiopia. Global J Med Public Health. 2014;3(3):45-67.

22. Adedokun ST, Adekanmbi VT, Uthman OA, Lilford RJ. Contextual Factors Associated with Health Care Service Utilization for Children with Acute Childhood Illnesses in Nigeria. PLoS One. 2017;12(3):e0173578.

23. Arthur E. Socioeconomic Correlates and the Choice of Treatment for Childhood Fever in Ghana. Afr Popul Stud. 2014;28(2):946-55.

24. Arthur E. The Effect of Household Socioeconomic Status on the Demand for Child Health Care Services. Afr Dev Rev. 2019;31(1):87-98.

25. Patil SC, Dixit P. Health Seeking Behavior among $0-5$ Years of Children in Diarrhea in Rural Wardha District, Maharashtra. Primary Health Care. 2018; 8(2):298.

26. Adane M, Mengistie B, Mulat W, Kloos H, Medhin G. Utilization of health facilities and predictors of health-seeking behavior for under-five children with acute diarrhea in slums of Addis Ababa, Ethiopia: a community-based cross-sectional study. J Health Population Nutr. 2017:36:9.

27. Abdulkadir MB, Abdulkadir ZJ. A Cross-Sectional Survey of Parental CareSeeking Behavior for Febrile Illness among Under-five Children in Nigeria. Alexandria J Med. 2017;53(1):85-91.

28. Gelaw YA, Biks GA, Alene KA. Effect of Residence on Mothers' Health Care Seeking BCehavior for Common Childhood Illness in Northwest Ethiopia: A Community Based Comparative Cross - Sectional Study. BMC Res Notes. 2014;7:705.

29. Adinan J, Damian DJ, Mosha NR, Mboya IB, Mamseri R, Msuya SE: Individual and Contextual Factors Associated with Appropriate Healthcare Seeking Behavior among Febrile Children in Tanzania. PLoS ONE. 2017;12(4):1-15.

30. Uggla C, Mace R. Parental Investment in Child Health in Sub-Saharan Africa: A Cross-National Study of Health-Seeking Behaviour. R Soc Open Sci. 2016;3: 150460.

31. Adedokun ST, Uthman OA, Adekanmbi VT, Wiysonge CS. Incomplete childhood immunization in Nigeria: a multilevel analysis of individual and contextual factors. BMC Public Health. 2017;17(236):1-10.

\section{Publisher's Note}

Springer Nature remains neutral with regard to jurisdictional claims in published maps and institutional affiliations.
Ready to submit your research? Choose BMC and benefit from:

- fast, convenient online submission

- thorough peer review by experienced researchers in your field

- rapid publication on acceptance

- support for research data, including large and complex data types

- gold Open Access which fosters wider collaboration and increased citations

- maximum visibility for your research: over $100 \mathrm{M}$ website views per year

At BMC, research is always in progress.

Learn more biomedcentral.com/submissions 